\title{
SEOM clinical guideline for the management of immune-related adverse events in patients treated with immune checkpoint inhibitors (2019)
}

\author{
M. Majem ${ }^{1,13}$ (D) E. García-Martínez ${ }^{2,13} \cdot$ M. Martinez $^{3} \cdot$ E. Muñoz-Couselo ${ }^{4} \cdot$ D. Rodriguez-Abreu ${ }^{5,13} \cdot$ R. Alvarez $^{6}$. \\ A. Arance ${ }^{7,13} \cdot$ A. Berrocal $^{8} \cdot$ L. de la Cruz-Merino $9,10,13 \cdot$ J. A. Lopez-Martin ${ }^{11,12,13}$
}

Received: 16 December 2019 / Accepted: 16 December 2019 / Published online: 28 January 2020

(c) The Author(s) 2020

\begin{abstract}
The use of immune checkpoint inhibitors has emerged as an effective treatment option for patients with several tumor types. By increasing the activity of the immune system, they can induce inflammatory side effects, which are often termed immunerelated adverse events. These are pathophysiologically unique toxicities, compared with those from other anticancer therapies. In addition, the spectrum of the target organs is very broad. Immune-inflammatory adverse events can be life threatening. Prompt diagnosis and pharmacological intervention are instrumental to avoid progression to severe manifestations. Consequently, clinicians require new skills to successfully diagnose and manage these events. These SEOM guidelines have been developed with the consensus of ten medical oncologists. Relevant studies published in peer-review journals were used for the guideline elaboration. The Infectious Diseases Society of America grading system was used to assign levels of evidence and grades of recommendation.
\end{abstract}

Keywords Immunotherapy $\cdot$ irAEs · Toxicity

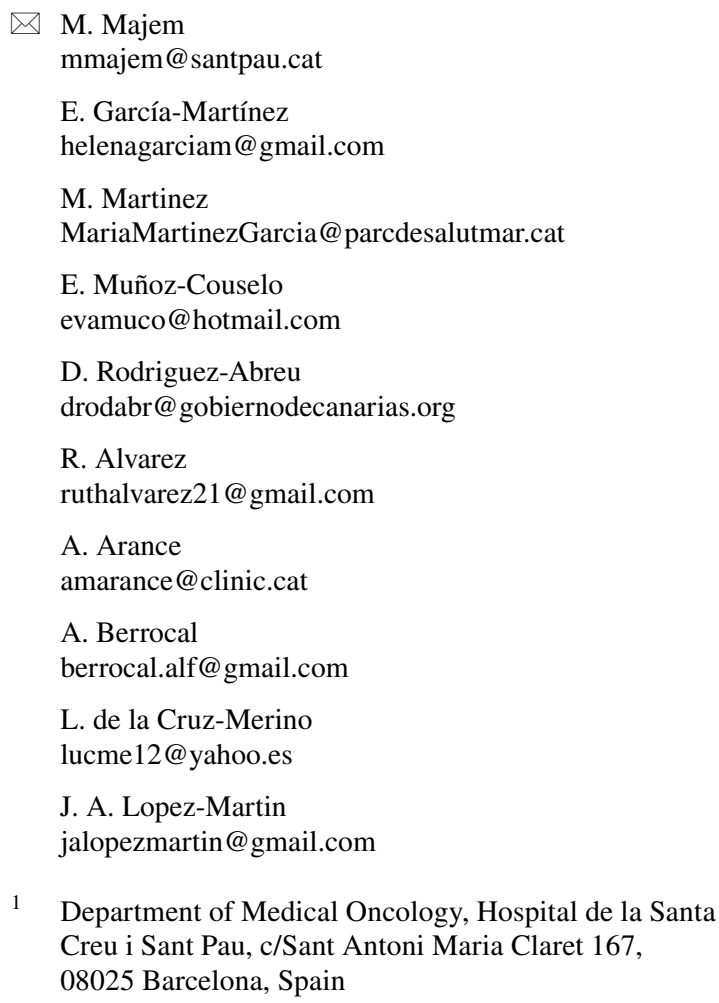

Department of Medical Oncology and Hematology, Hospital Universitario Morales Meseguer, Murcia, Spain

3 Department of Medical Oncology, Hospital del Mar, Barcelona, Spain

4 Department of Medical Oncology, Melanoma and Other Skin Tumors Unit, Vall d'Hebron Hospita, Vall d'Hebron Institute of Oncology VHIO, Barcelona, Spain

5 Department of Medical Oncology, C.H.U. Insular-Materno Infantil de Gran Canaria, Las Palmas, Spain

6 Department of Medical Oncology, Hospital Virgen de la Salud, Toledo, Spain

7 Department of Medical Oncology, Hospital Clínic, Barcelona, Spain

8 Department of Medical Oncology, Consorcio Hospital General Universitario de Valencia, Valencia, Spain

9 Clinical Oncology Department, Hospital Universitario Virgen Macarena, Seville, Spain

10 Medicine Department, Universidad de Sevilla, Sevilla, Spain

11 Department of Medical Oncology, Hospital Universitario, 12 de Octubre, Madrid, Spain

12 Clinical and Translational Oncology, Instituto de Investigación Sanitaria Hospital, 12 de Octubre, Madrid, Spain

13 Spanish Group for Cancer Immuno-Biotherapy, GÉTICA, Madrid, Spain 


\section{Introduction: landscape of adverse events induced by cancer immunotherapies}

The use of immune checkpoint inhibitors (ICI), such as inhibitors of cytotoxic T-lymphocyte antigen 4 (CTLA-4) and programmed cell death 1 (PD-1) or its ligand, programmed cell death ligand 1 (PD-L1), has emerged as effective treatment options for patients with several tumor types. By increasing the activity of the immune system, ICI can induce inflammatory side effects, which are often termed immune-related adverse events (irAEs). These are pathophysiologically unique toxicities compared with those from other anticancer therapies. The severity of irAEs is graded according to the Common Terminology Criteria for Adverse Events (CTCAE) [1, 2].

The frequency of irAEs varies according to the specific class of compounds and patient population. Grade 3-4 toxicities have been reported in 10-27\% of patients receiving anti-CTLA-4, and in 7-20\% of patients receiving anti-PD-1/anti-PD-L1 agents [3]. Fatigue is a commonly reported toxicity, with a frequency of $12-37 \%$ of patients receiving an anti-PD-1/anti-PD-L1, and most of the times is not associated with a treatable reason [3]. These frequencies can increase significantly when these drugs are given in combination with another ICI or with chemotherapy $[3,4]$. Not only the spectrum of target organs is very broad (Table 1) [5, 6], but also the timing and temporal evolution of the irAEs. The latter also depends on the class of ICI, but, in general, skin toxicity can appear after 2 weeks, endocrine events can have a delayed onset and liver and gastrointestinal toxicities may arise at intermediate time points. All these toxicities can become accelerated when ICIs are combined. Consequently, clinicians require new skills to successfully diagnose and manage these events properly.

Several guidelines have been published [3, 7-9]; for this reason, we will emphasize on key general points regarding the management of irAEs, including severe and/or treatment refractory irAEs.

\section{Methodology}

These SEOM guideline have been developed with the consensus of ten medical oncologists from Spanish Society of Medical Oncology (SEOM) and Spanish Group for Cancer Immune-Biotherapy (GÉTICA). Relevant studies published in peer-review journals were used for the elaboration of the guideline. The Infectious Diseases Society of America grading system was used to assign levels of evidence and grades of recommendation [10].

\section{General principles for the management of immune-related adverse events}

Immune-inflammatory adverse events can be life threatening [11]. Prompt diagnosis and pharmacological intervention are instrumental to avoid progression to severe manifestations [V, A] [1, 7, 12]. For such purposes, sharing adequate information with patients and their families, other treating physicians (including primary care and emergency room),

Table 1 Immune-related adverse events of affected organs

\begin{tabular}{|c|c|c|}
\hline \multirow[t]{2}{*}{ Organ system } & \multicolumn{2}{|l|}{ Types of irAEs } \\
\hline & Frequent & Rare or infrequent \\
\hline Cutaneous & Rash, pruritus, vitiligo & $\begin{array}{l}\text { Acneiform rash, alopecia, bullous pemphigoid, papulopustular rosacea, psoriasis, } \\
\text { Stevens-Johnson syndrome, toxic epidermal necrosis, Sweet syndrome }\end{array}$ \\
\hline Gastrointestinal & Diarrhea, colitis, lichenoid mucositis & Enteritis, gastritis, pancreatitis \\
\hline Endocrine & $\begin{array}{l}\text { Hypothyroidism, hyperthyroidism, thy- } \\
\text { roiditis, hypophysitis }\end{array}$ & Autoimmune type 1 diabetes, primary adrenal insufficiency \\
\hline Hepatic & Transaminitis, hepatitis & - \\
\hline Respiratory & Pneumonitis & Pleuritis, sarcoidosis \\
\hline Rheumatologic & Arthralgia, inflammatory arthritis, myalgia & $\begin{array}{l}\text { Dermatomyositis, myositis, polymyalgia-like syndrome, Sjörgren syndrome, } \\
\text { vasculitis }\end{array}$ \\
\hline Renal & Increase in serum creatinine, nephritis & - \\
\hline Ocular & - & Uveitis, conjunctivitis, scleritis, episcleritis, blepharitis, retinitis \\
\hline Neurological & Sensorimotor neuropathy & $\begin{array}{l}\text { Aseptic meningitis, autonomic neuropathy, encephalitis, facial nerve palsy, Guil- } \\
\text { lain-Barré syndrome, myasthenia gravis, posterior reversible leukoencepha- } \\
\text { lopathy, transverse myelitis }\end{array}$ \\
\hline Hematological & - & $\begin{array}{l}\text { Aplastic anemia, hemolytic anemia, idiopathic thrombocytopenic purpura, lym- } \\
\text { phopenia, hemophilia }\end{array}$ \\
\hline Cardiac & - & Cardiomyopathy, myocarditis, pericarditis \\
\hline
\end{tabular}


Table 2 General recommendations for the management of IO toxicities $(3,8)$

\begin{tabular}{|c|c|c|}
\hline $\begin{array}{l}\text { irAE } \\
\text { CTCAE } \\
\text { grade }\end{array}$ & Recommendation & Comments \\
\hline 1 & $\begin{array}{l}\text { Symptom management, usually without systemic glucocorti- } \\
\text { coids }\end{array}$ & Usually can continue ICI \\
\hline 2 & $\begin{array}{l}\text { Consider systemic glucocorticoid (Table } 3 \text { ) (oral prednisone, iv } \\
\text { methylprednisolone } 1-2 \mathrm{mg} / \mathrm{Kg} / \text { day) } \\
\text { If no improvement in } 2-3 \text { days, escalate glucocorticoid dose to } \\
2 \mathrm{mg} / \mathrm{Kg} / \text { day } \\
\text { Once improved to at least grade } 1 \text {, taper slowly ( } 4-6 \text { weeks) }\end{array}$ & $\begin{array}{l}\text { Withhold immunotherapy until grade } 1 \text { and prednisone } \\
\text { dose } \leq 10 \mathrm{mg} \\
\text { Consider PJP prophylaxis, calcium/vitamin D. Check blood } \\
\text { glucose }\end{array}$ \\
\hline $3-4$ & $\begin{array}{l}\text { Systemic glucocorticoid (Table } 3 \text { ) (oral prednisone, iv methyl- } \\
\text { prednisolone } 1-2 \mathrm{mg} / \mathrm{Kg} / \text { day) } \\
\text { If no improvement in } 2-3 \text { days, add another immune suppressant } \\
\text { (Table } 3 \text { ), according to specific toxicity recommendations } \\
\text { Once improved to at least } \mathrm{G} 1 \text {, taper slowly (4-6 weeks) }\end{array}$ & $\begin{array}{l}\text { Withhold immunotherapy until G1 without corticosteroids } \\
\text { Consider PJP prophylaxis, calcium/vitamin D. Check blood } \\
\text { glucose } \\
\text { Grade 3-consider discontinuation of immunotherapy, depending } \\
\text { on duration and target organ (see specific guidelines) } \\
\text { Grade 4-discontinue immunotherapy }\end{array}$ \\
\hline
\end{tabular}

irAEs immune-related adverse event, CTCAE National Cancer Institute Common Toxicity Criteria for Adverse Events, ICI immune-checkpoint Inhibitor, PJP Pneumocystis jiroveci pneumonia

Table 3 Main characteristics of immunosuppressive agents recommended in IO toxicity management

\begin{tabular}{lll}
\hline Therapy & Common schedules & irAE \\
\hline Corticosteroids & Oral/IV prednisone $0,5-2 \mathrm{mg} / \mathrm{kg} /$ day & From grade $\geq 2$ irAEs, in any toxicity \\
& IV methylprednisolone $1-2 \mathrm{mg} / \mathrm{kg} / \mathrm{day}$ & \\
Anti-TNF $\alpha$ & Infliximab $5 \mathrm{mg} / \mathrm{kg}$ once every 2 weeks & CRT, especially in colitis, pneumonitis, myocarditis \\
Anti-IL6 & Tocilizumab $8 \mathrm{mg} / \mathrm{kg}$ iv once per month & CRT, alternative to anti-TNF $\alpha$, especially in myocarditis \\
Anti-IL1 & Anakinra $100 \mathrm{mg}$ once per day or canakizumab & CRT, alternative to anti-TNF $\alpha$, especially in myocarditis \\
Mycophenolate mofetil & 300-600 mg once every 8 weeks & \\
Anti-CD20 & Rituximab $375 \mathrm{mg} / \mathrm{m} 2$ iv once weekly for 4 weeks & CRT, especially in hepatitis, and myocarditis \\
& & Multirefractory toxicity, especially in SLE, Sjögren \\
Immunoglobulins & Immunoglobulins iv $400 \mathrm{mg} / \mathrm{kg}$ per day, 5 days & GBS, MG, encephalitis and other neurological irAEs \\
Plasmapheresis & Several courses as needed & GBS, other neurological irAEs
\end{tabular}

$C R T$ corticosteroid refractory toxicity, SLE systemic lupus erythematosus, GBS Guillain-Barré syndrome, irAEs immune-related adverse events, $A T G$ antithymocyte globulin

pharmacists, and nurses is essential. Patients should be instructed on how to act or when to consult, and contact persons should be defined. Managing irAEs frequently involve other specialists, such as dermatologists, gastroenterologists, neurologists, endocrinologists, and others, who should become aware of these toxicities [12].

As shown in Table 2, grade 2 irAEs usually require withholding ICI and close monitoring, and to decide if systemic corticosteroids (prednisone, initial dose of 0.5 to $1 \mathrm{mg} / \mathrm{kg} /$ day, or equivalent) should be initiated [V, A] [7]. For most of the grade 1 irAEs, ICIs can be continued, with some exceptions (e.g., neurologic or cardiac toxicities) [7]. Grade 3-4 irAEs must be treated with high-dose corticosteroids (prednisone 1 to $2 \mathrm{mg} / \mathrm{kg} /$ day, or methylprednisolone IV 1 to $2 \mathrm{mg} / \mathrm{kg} /$ day) [V, A] [7]. Once initiated, corticosteroids should be tapered over 4-6 weeks. If there is no improvement after 48-72 h, consider other immunosuppressors [V,
A] [7] (Table 3). Dose adjustments of ICIs are not recommended [7]. No prophylactic role has been demonstrated for steroids [II, D] [13].

\section{Patient selection and baseline assessments}

Baseline assessments are recommended before starting treatment to rule out susceptibility to develop irAEs. These include a complete patient and family history, general physical condition, concomitant herbs and medication. Baseline laboratory tests may include complete blood counts, renal, liver and pancreatic functions tests, hormonal axis tests and viral serologies [V, C].

Due to ICI mechanism of action, several groups of patients have been excluded from clinical trials, including patients with chronic infectious diseases (hepatitis B and C, HIV), transplant recipients or patients with autoimmune 
diseases. These challenging patients should be managed by multidisciplinary teams and followed up closely [V, A]. ICIs appear to be relatively safe in patients with autoimmune diseases [14] [V, B], as well as in chronic viral hepatitis [III, B]. HIV infection should not be a contraindication for ICI, although patients with low CD4 counts should be monitored closely for efficacy and immune reconstitution [III, B]. ICIs have very high risk of causing post-transplant complications and organ rejection [V, A]. Ipilimumab appears to have superior safety in this setting [V, B]. Anti-PD-1/PD-L1 therapy can result in spontaneous abortion in pregnant women and should be avoided [15] [V, A].

\section{Specific recommendations}

\section{Management of frequent toxicities}

\section{Management of gastrointestinal toxicity}

Epidemiology Gastrointestinal toxicities are among the leading causes of immune-related adverse effects of ICIs. The frequency with anti-CTLA- 4 of diarrhea is $23-33 \%$ and $3-6 \%$ for grade $3-4$ colitis, $[16,17]$ and with anti-PD-1/ PD-L1 the frequency of diarrhea is $11-19 \%$ and $1-4 \%$ for grade 3-4 colitis [18]; the frequency of the combination anti-CTLA-4 and anti-PD-1/PDL1is up to $45 \%$, grade $3 / 4$, 9-11\% [19].

Clinical presentation The median onset of diarrhea is approximately 6-8 weeks after initiation of therapy and $1 / 3$ of patients have concurrent enteritis $[12,20]$.

Diagnosis Diagnosis is based on duration, severity, and presence of alarm features that may require hospital admission [21]. Patients should undergo a complete blood count, serum electrolyte profile, serum albumin and serum C-reactive protein. Stool analyses for enteropathogens and Clostridium difficile toxin analysis should be carried out [20, 21]. Abdominal imaging is not routinely required in patients with grade 1-2 diarrhea. In severe cases, abdominal CT may be indicated to rule out complications [22]. Flexible sigmoidoscopy or colonoscopy should be performed in patients with bloody diarrhea or those with persistent $\geq$ grade 2 diarrhea [23] [IV, D].

Management See Fig. 1 [3, 24-28] [V, B].

\section{Management of hepatic toxicity [29-32]}

Epidemiology It has been described in 5-10\% (1-2\% grade 3 ) of patients receiving monotherapy and in $25-30 \%(15 \%$ grade 3 ) of patients receiving combination of ICIs.
Clinical presentation Hepatitis induced by ICIs appears approximately 6-8 weeks after initiation of therapy and usually consists of an asymptomatic elevation of transaminases. Severe hepatotoxicity involving liver injury with jaundice, and other signs and symptoms of hepatic failure is not frequent.

Diagnosis Initial workup includes a blood test with serum transaminases, bilirubin and prothrombin time $[\mathrm{V}, \mathrm{A}]$, as well as the exclusion of other causes of transaminase increase such as infectious disease, liver metastasis, concomitant drugs or alcohol intake $[\mathrm{V}, \mathrm{A}]$. Liver biopsy $[\mathrm{V}, \mathrm{C}]$ may be needed in case of severe or corticosteroid-refractory hepatitis and may help to dismiss other causes of liver toxicity or tumor infiltration.

Management See Fig. 2 [V, A]. A multidisciplinary management is essential in the treatment of hepatic toxicity.

\section{Management of endocrine events}

Epidemiology Endocrine AEs occur in 10\% of patients receiving ICIs [33]. Hypophysitis is more frequent with antiCTLA-4 and thyroid dysfunction with anti-PD-1/PD-L1 drugs. Other uncommon irAEs include primary adrenal insufficiency, Graves' disease, Graves' ophthalmopathy and autoimmune diabetes mellitus.

Clinical presentation Endocrine toxicities usually present with nonspecific symptoms that make them difficult to suspect and many of them are irreversible due to the permanent damage of the affected gland [34]. The most common are those affecting the thyroid gland, which are usually grade $\leq 2$. These occur due to a transient inflammation of the gland, which can present with overproduction of thyroid hormone (hyperthyroidism) or underproduction (hypothyroidism).

Diagnosis and treatment See Fig. 3 [V, A]. Hyperthyroidism usually does not need active treatment, although it may evolve to hypothyroidism. Hypothyroidism is usually a permanent condition that needs levothyroxine substitution for life. Hypophysitis can affect one or several of the pituitary axes with or without a pathological image in the MRI. The steroid axis is the most frequently affected permanently [35]. In these patients, any additional stress can cause an acute adrenal crisis, seriously threatening patient's life and requiring urgent treatment. For grade $\geq 3$ toxicity to seek endocrinology consultation is recommended. 


\title{
Symptom grade
}

\section{Management}
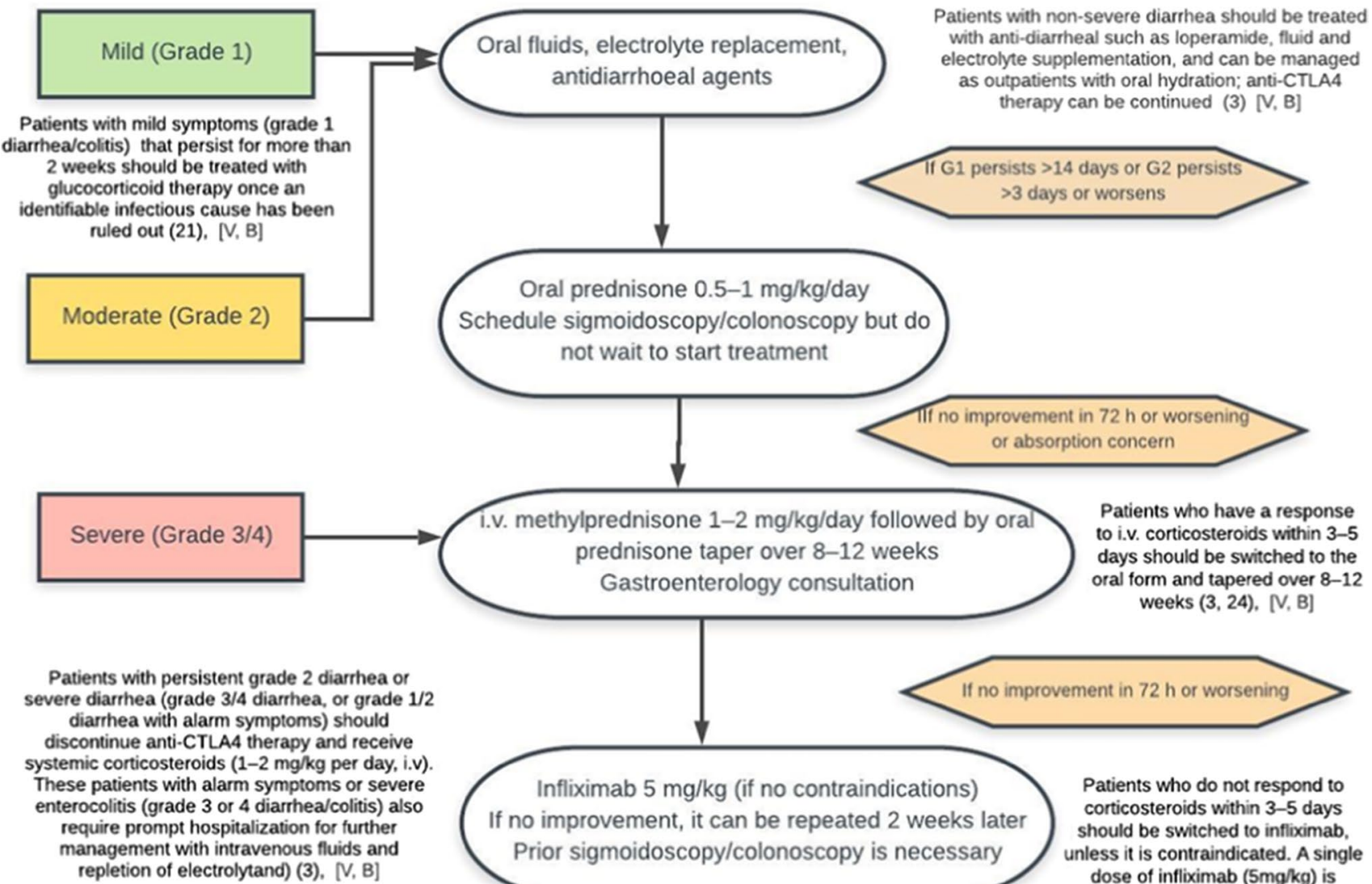

i.v. methylprednisone $1-2 \mathrm{mg} / \mathrm{kg} /$ day followed by oral prednisone taper over 8-12 weeks Gastroenterology consultation
Patients who have a response to i.v. corticosteroids within 3-5 days should be switched to the oral form and tapered over 8-12

\begin{abstract}
weeks $(3,24),[\mathrm{V}, \mathrm{B}]$
\end{abstract}

\begin{abstract}
Patients with persistent grade 2 diarrhea or vere diarrhea (grade 3/4 diarrhea, or grade $1 / 2$ diarrhea with alarm symptoms) should discontinue anti-CTLA4 therapy and receive These patients with al $(1-2 \mathrm{mg} / \mathrm{kg}$ per day, i.v). terocolitis (grade 3 or 4 diarthea/colitis) also management with intravenous fluids and repletion of electrolytand) (3), [V, B]
\end{abstract}

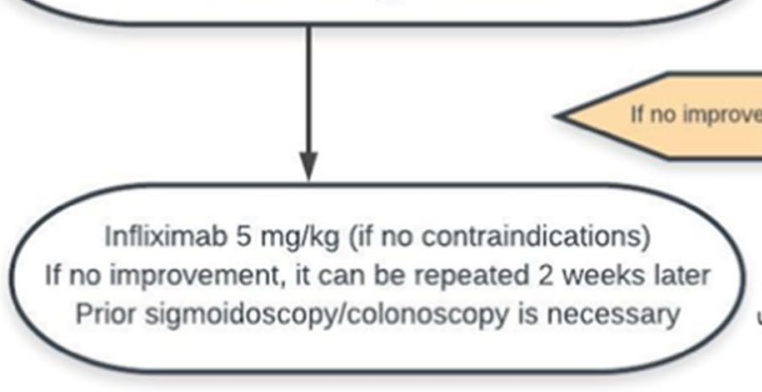

\begin{abstract}
- Overall, one-third to two thirds of patients either do not respond to high-dose i.v. steroids, or have a relapse requiring an increase in the corticosteroid dosage during the course of steroid tapering $(3,26,27)$.

- Some patients develop a colonic perforation, with or without intra-abdominal abscess, either initially or during the course of medical treatment and they should have emergency colectomy $(3,21)$.

- Development of diarrhea and/or colitis during use of one checkpoint inhibitor does not necessarily prohibit the use of another and treatment with nivolumab after ipilimumab seems to be safe (28).
\end{abstract}

Fig. 1 Management of gastrointestinal toxicity

\section{Management of pneumonitis}

Epidemiology Pneumonitis occurs predominantly in patients receiving anti-PD-1/PD-L1 alone or combination with anti-CTLA-4 [36]. The incidence is higher in patients with lung and renal cell cancer, suggesting that chemotherapy-induced lung inflammation, previous radiotherapy, pre-existing lung disease or smoking may contribute to the occurrence of this toxicity [37].

Clinical presentation Pneumonitis can mimic other symptoms encountered in cancer patients including dyspnea and nonproductive cough. Fever and chest pain are less common.
Diagnosis Patients should undergo a chest CT scan as chest X-ray may fail to identify about $25 \%$ of cases of pneumonitis [38]. Several patterns of radiological presentation have been reported, being cryptogenetic organizing pneumonia the most frequent [36].

Management Treatment of incidental radiographic changes is controversial, and most guidelines suggest delaying treatment until radiographic improvement or resolution [V, C]. For grade 2 pneumonitis, treatment with oral steroids is indicated (prednisone $1 \mathrm{mg} / \mathrm{kg} /$ day) and ICIs should be withheld [V, B]. Grade $\geq 3$ pneumonitis requires hospitalization and treatment with I.V. steroids (methyl/prednisolone 2-4 mg/kg/day), and ICIs should be permanently discontin- 


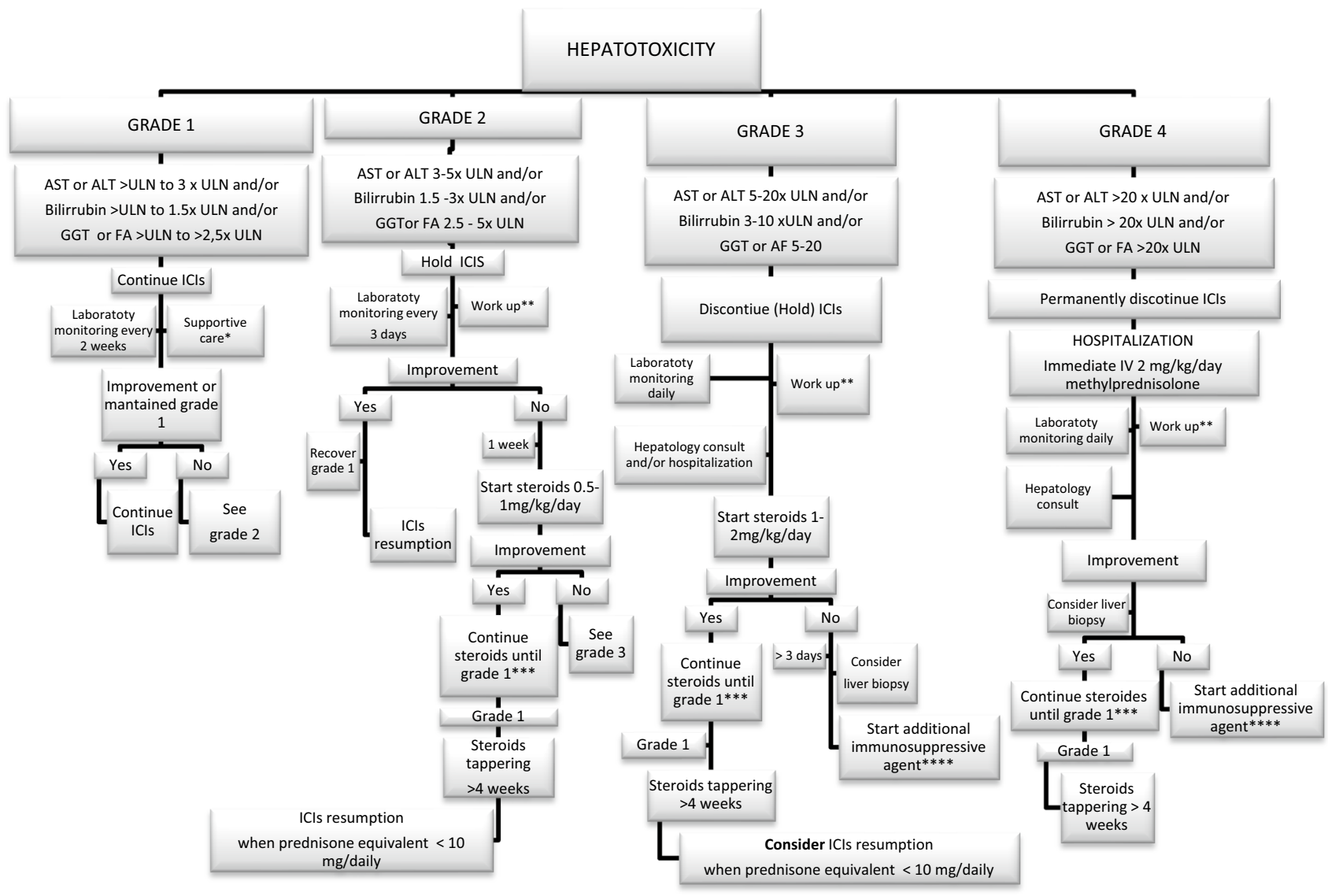

Fig. 2 Management of hepatic toxicity. *Supportive care: avoid alcohol and hepatotoxic drugs. Supportive treatment in case of symptoms. **Workup: review concomitant medications, herbs, dietary supplements, homeopathic. Liver function test, prothrombin time, albumin, serology hepatitis, autoimmune and iron studies, investigate new

ued [V, B]. A bronchoscopy should be performed to exclude infectious etiologies before starting immunosuppression. Infliximab and/or cyclophosphamide should be considered for refractory pneumonitis [3, 7-9].

\section{Management of cutaneous adverse events [39, 40]}

Epidemiology Cutaneous side effects are common under ICIs (anti-CTLA-4: 43-45\%, anti-PD-1/PD-L1: 35\%), and may be serious and dose limiting. Cutaneous adverse events appear later with anti-PD-1/PD-L1 than with anti-CTLA-4 or combination.

Clinical presentation The most frequently reported cutaneous adverse events are maculo-papular rash, pruritus and vitiligo. Exacerbation of psoriasis or psoriasiform and lichenoid reactions has also been reported.

Diagnosis Careful physical examination of the skin and mucosal areas is required. Blood tests may be helpful if metastasis. $* * *$ If steroids therapy if required $>2$ weeks consider prophylactic antibiotic. $* * * *$ Additional immunosuppressive medications include mycophenolate mofetil, tacrolimus, antithymocyte globulin, or cyclosporine

life-threatening syndromes are suspected. Skin biopsy and a review by dermatologist may also be indicated.

Management ICIs can be maintained in grade 1-2 toxicities, interrupted in grade 3 and permanently discontinued in grade 4 [V, A]. Symptomatic treatment with systemic antihistamines, high to very high strength topical steroids, and topical moisturizers is indicated in all grades [V, A]. Highdose steroids are indicated in grade $\geq 3$. Other immunosuppressive drugs may be needed in steroid-refractory cases [V, A].

\section{Management of less frequent toxicities}

\section{Management of neurological toxicity}

Epidemiology and clinical presentation The incidence of neurological complications varies from 2-4\% [1, 41, 42]. Moderate AEs have been reported in 6-12\% (dizziness, headaches, sensory neuropathies, etc.), whereas severe 


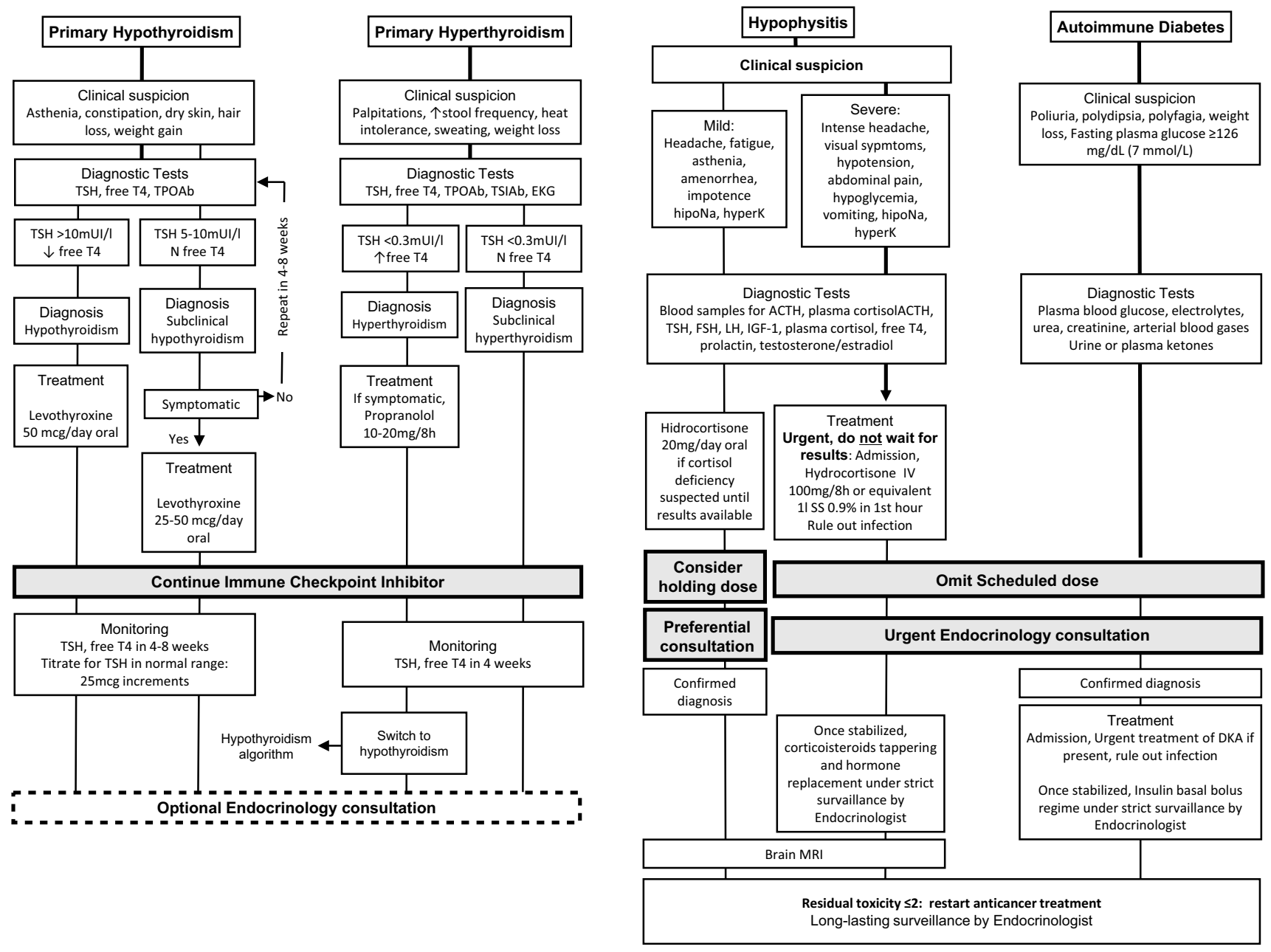

Fig. 3 Management of endocrine toxicity. TSH thyrotropin-stimulating hormone, TPOA $b$ anti-peroxidase antibodies, TSIA $b$ anti-TSH receptor antibodies, SS saline solution $0.9 \%$

events (encephalitis, aseptic meningitis, inflammatory myopathies, myasthenia gravis, Guillain-Barre syndrome, multiple sclerosis, etc.) are present in $<1 \%$ of patients. This incidence can be higher when ICIs are given in combination $(14 \%)$, or if there is preexisting autoimmune disease $(27-38 \%)$ [1, 41, 43-45].

Management A neurologic consult is indicated. There is no standard therapy and treatment is decided according to the type and severity of the neurological event. Improvements have been described after discontinuation of ICIs and with systemic high-dose steroids [V, B]. Other treatments such as intravenous immunoglobulin, plasmapheresis or immunosuppressive agents have shown non-consistent results [V, B]. After neurological toxicity recovery, resumption of ICIs is controversial, and risk/benefit ratio should be carefully taken into consideration [46].

\section{Management of cardiovascular toxicity}

Epidemiology and clinical presentation The incidence of cardiac toxicity is $<1 \%$, although it might have been underreported and/or underestimated. The incidence is higher with the combination of anti-CTLA-4 and anti-PD-1/PD-L1 $(0.27 \%)$ compared with anti-PD-1/PD-L1 alone (0.06\%). A wide range of toxicities, including myocarditis, pericarditis, arrhythmias, cardiomyopathy and decrease in ventricular function, have been reported [47].

Diagnosis and management Initial workup may include EKG, troponin, BNP and echocardiogram. Early consultation with a cardiologist is highly recommended $[\mathrm{V}, \mathrm{B}]$ and additional testing with cardiac MRI may be indicated. Highdose steroids have been used successfully and should be given quickly if suspected [V, B]. Other immunosuppressive drugs such as mycophenolate, infliximab, or antithymocyte globulin may be indicated if patient does not respond to ster- 
oids [V, B] [3]. Infliximab in contraindicated in the presence of moderate to severe heart failure.

\section{Management of renal toxicity}

Epidemiology and clinical presentation Renal toxicity is rare in patients receiving monotherapy $(<1 \%)$ but can reach $5 \%$ when ICIs are combined together or with a platinumbased chemotherapy. The most common event is acute tubule-interstitial nephritis.

Diagnosis and management Renal function should be measured before every infusion of ICI and nephrotoxic drugs may be stopped in case of renal dysfunction. Presence of infection or urinary tract obstruction must be evaluated. ICI should be interrupted in grade $\geq 2$ renal dysfunction and treatment with high-dose steroids is recommended [V, B]. Nephrology evaluation is also recommended and a renal biopsy may be useful [V, B] [3, 48].

\section{Management of rheumatologic toxicity}

Epidemiology and clinical presentation Incidence of rheumatologic toxicity is generally underestimated and is more common with anti-PD-1/PD-L1. They can be grouped in inflammatory arthritis, myositis, and polymyalgia rheumatica (PMR)-like syndromes [49].

Diagnosis and management A multidisciplinary approach would be the first measure. Comprehensive anamnesis including joint examination and muscle strength, autoimmune blood panels and inflammatory markers, and radiological assessment with plain-X ray, ultrasound and or MRI is recommended [50] [V, D]. For grade 1 events, common analgesia with paracetamol or NSAIDs is recommended. From $\geq$ grade 2, referral to rheumatologist, temporary or permanent discontinuation of ICIs, steroids and biologic disease-modifying anti-rheumatic drugs must be considered [51] [V, D].

\section{Management of ocular toxicities}

Epidemiology and clinical presentation Ocular toxicities represent $<1 \%$ of irAEs [52] and consist of ocular inflammation (uveitis, peripheral keratitis, Vogt-Koyanagi-Harada syndrome), orbital inflammation, as well as retinal and choroidal diseases (retinopathy, neovascularization) [53]. Previous trials have shown that patients who develop ocular toxicities are more likely to present other irAEs. Uveitis has been reported in patients treated with anti-CTLA-4 and anti-PD-1 [54]. Idiopathic orbital inflammation has been described in relation to ipilimumab [52, 55]. Choroidal neovascularization has been reported in a patient treated with ipilimumab [56], requiring intravitreal anti-VEGF injections.

Diagnosis and management Treatment of ocular toxicities depends on the severity and type of toxicity. In case of uveitis, topical steroids can be effective, and for more severe toxicities, systemic steroids are indicated and discontinuation of ICIs should be considered [V, B]. Resumption can be considered in patients with grade 1-2 ocular toxicities but in case of grade $\geq 3$, permanent discontinuation should be recommended $[\mathrm{V}, \mathrm{B}]$.

\section{Management of refractory toxicities (Table 3)}

Epidemiology of steroid-refractory high-grade irAEs is currently unknown. Due to the lack of validated biomarkers, a gradual approach is advocated to manage severe irAEs, starting with high-dose steroids. If the latter fails, a more aggressive immunosuppression is recommended, considering the introduction of cytokine-directed $\mathrm{mAb}$ against IL-1, IL-6 or TNF $\alpha[11,57]$. Anti-TNF $\alpha$ mAb infliximab (single dose of $5 \mathrm{mg} / \mathrm{kg}$ ) is the upfront recommended treatment for corticosteroid-refractory colitis and pneumonitis, and mycophenolate mofetil with appropriate antibacterial and antiviral prophylaxis for corticosteroid-refractory hepatitis [V, C], although use of anti-IL6 (tocilizumab) and anti-IL1 (anakinra) may represent good alternatives for the previous and many other irAEs in the context of a personalized approach with close monitorization [7] [V, D]. Immunoglobulins and plasmapheresis could be an option in severe and multirefractory irAEs, especially in neurological irAEs [8] [IV, D].

\section{Conclusions}

ICIs are an effective treatment option in several tumor types that can induce inflammatory side effects, termed irAES. irAEs can affect multiple organs of the body and its severity can be low to life threatening. As a consequence, clinicians require new skills to successfully diagnose and manage these events, and also a multidisciplinary approach may be indicated.

Author contributions All the authors have contributed equally to the writing of the manuscript.

\section{Compliance with ethical standards}

Conflict of interest MMT reports grants and personal fees from BMS; personal fees from Astra Zeneca, Roche, MSD, Boehringer Ingelheim, Takeda, and Bayer; non-financial support and other from Astra Zeneca, MSD, Boehringer Ingelheim, and other from Takeda, outside the 
submitted work; EGM reports grants and personal fees from Roche, Astra Zeneca, MSD, BMS, Pfizer, and Pharmamar, outside the submitted work; MMG reports personal fees and non-financial support from Roche, and non-financial support from Pfizer, outside the submitted work; AA reports personal fees and other from BMS, MSD, Roche, Novartis, Merck, Sanofi, Amgem, Pierre Fabre, outside the submitted work; AB reports personal fees and non-financial support from BMS, MSD, Roche, Novartis, Sanofi, Merck-Pfizer, personal fees from Pierre Fabre and Incyte, outside the submitted work; LC reports grants and personal fees from BMS, Roche, MSD-Merck, Amgen, personal fees from Pierre Fabre, Novartis, and grants from Celgene, outside the submitted work; JAL reports grants, personal fees, non-financial support and others from BMS-Celgene, MSD, Novartis-GSK, Roche and Pfizer, grants, non-financial support and others from Astra-Zeneca, and non-financial support and others from Amgen, Bayer, Daichi-Sankyo, Chobani, Pierre Fabre, personal fees, non-financial support and others from Pharmamar, and non-financial support from Merk-Serono during the conduct of the study; EM, DR and RA have nothing to disclose.

Ethical approval The current study has been performed in accordance with the ethical standards laid down in the 1964 Declaration of Helsinki and its later amendments.

Informed consent Not applicable.

Open Access This article is licensed under a Creative Commons Attribution 4.0 International License, which permits use, sharing, adaptation, distribution and reproduction in any medium or format, as long as you give appropriate credit to the original author(s) and the source, provide a link to the Creative Commons licence, and indicate if changes were made. The images or other third party material in this article are included in the article's Creative Commons licence, unless indicated otherwise in a credit line to the material. If material is not included in the article's Creative Commons licence and your intended use is not permitted by statutory regulation or exceeds the permitted use, you will need to obtain permission directly from the copyright holder. To view a copy of this licence, visit http://creativecommons.org/licenses/by/4.0/.

\section{References}

1. Postow MA, Sidlow R, Hellmann MD. Immune-related adverse events associated with immune checkpoint blockade. N Engl J Med. 2018;378(2):158-68.

2. US Department of Health and Human Services. Common Terminology Criteria for Adverse Events (CTCAE) Version 5.0 2017 [Available from: https://ctep.cancer.gov/protocoldevelop ment/electronic_applications/docs/CTCAE_v5_Quick_Refer ence 5 × 7 .pdf.

3. Haanen J, Carbonnel F, Robert C, Kerr KM, Peters S, Larkin $\mathrm{J}$, et al. Management of toxicities from immunotherapy: ESMO clinical practice guidelines for diagnosis, treatment and followup. Ann Oncol. 2017;28(4):119-42.

4. Martins F, Sofiya L, Sykiotis GP, Lamine F, Maillard M, Fraga $\mathrm{M}$, et al. Adverse effects of immune-checkpoint inhibitors: epidemiology, management and surveillance. Nat Rev Clin Oncol. 2019;16(9):563-80.

5. Menzies AM, Johnson DB, Ramanujam S, Atkinson VG, Wong ANM, Park JJ, et al. Anti-PD-1 therapy in patients with advanced melanoma and preexisting autoimmune disorders or major toxicity with ipilimumab. Ann Oncol. 2017;28(2):368-76.

6. Bowyer S, Prithviraj P, Lorigan P, Larkin J, McArthur G, Atkinson V, et al. Efficacy and toxicity of treatment with the
anti-CTLA-4 antibody ipilimumab in patients with metastatic melanoma after prior anti-PD-1 therapy. Br J Cancer. 2016;114(10):1084-9.

7. Brahmer JR, Lacchetti C, Schneider BJ, Atkins MB, Brassil KJ, Caterino JM, et al. Management of immune-related adverse events in patients treated with immune checkpoint inhibitor therapy: American society of clinical oncology clinical practice guideline. J Clin Oncol. 2018;36(17):1714-68.

8. Puzanov I, Diab A, Abdallah K, Bingham CO 3rd, Brogdon C, Dadu R, et al. Managing toxicities associated with immune checkpoint inhibitors: consensus recommendations from the society for immunotherapy of cancer (SITC) toxicity management working group. J Immunother Cancer. 2017;5(1):95.

9. Thompson JA, Schneider BJ, Brahmer J, Andrews S, Armand $\mathrm{P}$, Bhatia $\mathrm{S}$, et al. Management of immunotherapy-related toxicities, Version 1.2019. J Natl Compr Cancer Netw JNCCN. 2019;17(3):255-89.

10. Dykewicz CA. Summary of the guidelines for preventing opportunistic infections among hematopoietic stem cell transplant recipients. Clin Infect Dis. 2001;33(2):139-44.

11. Wang DY, Salem JE, Cohen JV, Chandra S, Menzer C, Ye F, et al. Fatal toxic effects associated with immune checkpoint inhibitors: a systematic review and meta-analysis. JAMA Oncol. 2018;4(12):1721-8.

12. Weber JS, Kahler KC, Hauschild A. Management of immunerelated adverse events and kinetics of response with ipilimumab. J Clin Oncol. 2012;30(21):2691-7.

13. Weber J, Thompson JA, Hamid O, Minor D, Amin A, Ron I, et al. A randomized, double-blind, placebo-controlled, phase II study comparing the tolerability and efficacy of ipilimumab administered with or without prophylactic budesonide in patients with unresectable stage III or IV melanoma. Clin Cancer Res. 2009;15(17):5591-8.

14. Pantuck M, McDermott D, Drakaki A. To treat or not to treat: patient exclusion in immune oncology clinical trials due to preexisting autoimmune disease. Cancer. 2019;125(20):3506-13.

15. Johnson DB, Sullivan RJ, Menzies AM. Immune checkpoint inhibitors in challenging populations. Cancer. 2017;123(11):1904-11.

16. Hodi FS, O'Day SJ, McDermott DF, Weber RW, Sosman JA, Haanen JB, et al. Improved survival with ipilimumab in patients with metastatic melanoma. N Engl J Med. 2010;363(8):711-23.

17. Wolchok JD, Neyns B, Linette G, Negrier S, Lutzky J, Thomas $\mathrm{L}$, et al. Ipilimumab monotherapy in patients with pretreated advanced melanoma: a randomised, double-blind, multicentre, phase 2, dose-ranging study. Lancet Oncol. 2010;11(2):155-64.

18. Larkin J, Chiarion-Sileni V, Gonzalez R, Grob JJ, Cowey CL, Lao $\mathrm{CD}$, et al. Combined nivolumab and ipilimumab or monotherapy in untreated melanoma. N Engl J Med. 2015;373(1):23-34.

19. Postow MA, Chesney J, Pavlick AC, Robert C, Grossmann $\mathrm{K}$, McDermott D, et al. Nivolumab and ipilimumab versus ipilimumab in untreated melanoma. $\mathrm{N}$ Engl $\mathrm{J}$ Med. 2015;372(21):2006-177.

20. Del Castillo M, Romero FA, Arguello E, Kyi C, Postow MA, Redelman-Sidi G. The spectrum of serious infections among patients receiving immune checkpoint blockade for the treatment of melanoma. Clin Infect Dis. 2016;63(11):1490-3.

21. Grover S, Rahma OE, Hashemi N, Lim RM. Gastrointestinal and hepatic toxicities of checkpoint inhibitors: algorithms for management. Am Soc Clin Oncol Educ. 2018;38:13-9.

22. Nishino M, Ramaiya NH, Hatabu H, Hodi FS. Monitoring immune-checkpoint blockade: response evaluation and biomarker development. Nat Rev Clin Oncol. 2017;14(11):655-68. 
23. Messmer M, Upreti S, Tarabishy Y, Mazumder N, Chowdhury R, Yarchoan M, et al. Ipilimumab-induced enteritis without colitis: a new challenge. Case Rep Oncol. 2016;9(3):705-13.

24. Gupta A, De Felice KM, Loftus EV Jr, Khanna S. Systematic review: colitis associated with anti-CTLA-4 therapy. Aliment Pharmacol Ther. 2015;42(4):406-17.

25. Beck KE, Blansfield JA, Tran KQ, Feldman AL, Hughes MS, Royal RE, et al. Enterocolitis in patients with cancer after antibody blockade of cytotoxic T-lymphocyte-associated antigen 4 . J Clin Oncol. 2006;24(15):2283-9.

26. Marthey L, Mateus C, Mussini C, Nachury M, Nancey S, Grange F, et al. Cancer immunotherapy with anti-CTLA-4 monoclonal antibodies induces an inflammatory bowel disease. J Crohns Colitis. 2016;10(4):395-401.

27. Verschuren EC, van den Eertwegh AJ, Wonders J, Slangen RM, van Delft F, van Bodegraven A, et al. Clinical, endoscopic, and histologic characteristics of ipilimumab-associated colitis. Clin Gastroenterol Hepatol. 2016;14(6):836-42.

28. Weber JS, Kudchadkar RR, Yu B, Gallenstein D, Horak CE, Inzunza HD, et al. Safety, efficacy, and biomarkers of nivolumab with vaccine in ipilimumab-refractory or -naive melanoma. J Clin Oncol. 2013;31(34):4311-8.

29. Haanen JBAG, Califano R, Lugowska I, Garassino MC. ESMO Handbook of immuno-oncology 2018.

30. Reynolds K, Thomas M, Dougan M. Diagnosis and management of hepatitis in patients on checkpoint blockade. Oncologist. 2018;23(9):991-7.

31. Nadeau BA, Fecher LA, Owens SR, Razumilava N. Liver toxicity with cancer checkpoint inhibitor therapy. Semin Liver Dis. 2018;38(4):366-78.

32. Rodriguez-Abreu D, García-Martínez E (2018) Aspectos clínicos específicos de las inmunoterapias: evaluación de su eficacia y manejo de su toxicidad. In: Lopez-Martin JA, Cruz-Merino Ldl, Rodriguez-Abreu D, Arance A (eds) Inmunoterapia del cáncer. Transworld Editors, Spain. pp. 197-227.

33. Barroso-Sousa R, Barry WT, Garrido-Castro AC, Hodi FS, Min L, Krop IE, et al. Incidence of endocrine dysfunction following the use of different immune checkpoint inhibitor regimens: a systematic review and meta-analysis. JAMA Oncol. 2018;4(2):173-82.

34. Gonzalez-Rodriguez E, Rodriguez-Abreu D. Immune checkpoint inhibitors: review and management of endocrine adverse events. Oncologist. 2016;21(7):804-16.

35. Albarel F, Gaudy C, Castinetti F, Carre T, Morange I, ConteDevolx B, et al. Long-term follow-up of ipilimumab-induced hypophysitis, a common adverse event of the anti-CTLA- 4 antibody in melanoma. Eur J Endocrinol. 2015;172(2):195-204.

36. Chuzi S, Tavora F, Cruz M, Costa R, Chae YK, Carneiro BA, et al. Clinical features, diagnostic challenges, and management strategies in checkpoint inhibitor-related pneumonitis. Cancer Manag Res. 2017;9:207-13.

37. Khoja L, Day D, Wei-Wu Chen T, Siu LL, Hansen AR. Tumourand class-specific patterns of immune-related adverse events of immune checkpoint inhibitors: a systematic review. Ann Oncol. 2017;28(10):2377-85.

38. Naidoo J, Wang X, Woo KM, Iyriboz T, Halpenny D, Cunningham J, et al. Pneumonitis in patients treated with anti-programmed death-1/programmed death ligand 1 therapy. J Clin Oncol. 2017;35(7):709-17.

39. Grávalos C, Sanmartín O, Gúrpide A, España A, Majem M, Suh $\mathrm{Oh} \mathrm{HJ}$, et al. Clinical management of cutaneous adverse events in patients on targeted anticancer therapies and immunotherapies: a national consensus statement by the Spanish Academy of Dermatology and Venereology and the Spanish Society of Medical Oncology. J Clin Transl Oncol. 2019;21(5):556-71.
40. Sibaud V. Dermatologic reactions to immune checkpoint inhibitors: skin toxicities and immunotherapy. Am J Clin Dermatol. 2018;19(3):345-61.

41. Wick W, Hertenstein A, Platten M. Neurological sequelae of cancer immunotherapies and targeted therapies. Lancet Oncol. 2016;17(12):e529-e541541.

42. Fellner A, Makranz C, Lotem M, Bokstein F, Taliansky A, Rosenberg S, et al. Neurologic complications of immune checkpoint inhibitors. J Neurooncol. 2018;137(3):601-9.

43. Kao JC, Liao B, Markovic SN, Klein CJ, Naddaf E, Staff NP, et al. Neurological complications associated with anti-programmed death 1 (PD-1) antibodies. JAMA Neurol. 2017;74(10):1216-22.

44. Larkin J, Chmielowski B, Lao CD, Hodi FS, Sharfman W, Weber J, et al. Neurologic serious adverse events associated with nivolumab plus ipilimumab or nivolumab alone in advanced melanoma, including a case series of encephalitis. Oncologist. 2017;22(6):709-18.

45. Gettings EJ, Hackett CT, Scott TF. Severe relapse in a multiple sclerosis patient associated with ipilimumab treatment of melanoma. Mult Scler. 2015;21(5):670.

46. Dalakas MC. Neurological complications of immune checkpoint inhibitors: what happens when you 'take the brakes off' the immune system. Ther Adv Neurol Disord. 2018;11:1756286418799864.

47. Upadhrasta S, Elias H, Patel K, Zheng L. Managing cardiotoxicity associated with immune checkpoint inhibitors. Chronic Dis Transl Med. 2019;5(1):6-14.

48. Murakami N, Motwani S, Riella LV. Renal complications of immune checkpoint blockade. Curr Probl Cancer. 2017;41(2):100-10.

49. Lidar M, Giat E, Garelick D, Horowitz Y, Amital H, SteinbergSilman Y, et al. Rheumatic manifestations among cancer patients treated with immune checkpoint inhibitors. Autoimmun Rev. 2018;17(3):284-9.

50. Cappelli LC, Shah AA, Bingham CO 3rd. Immune-related adverse effects of cancer immunotherapy: implications for rheumatology. Rheum Dis Clin N Am. 2017;43(1):65-78.

51. Suarez-Almazor ME, Kim ST, Abdel-Wahab N, Diab A. Review: immune-related adverse events with use of checkpoint inhibitors for immunotherapy of cancer. Arthritis Rheumatol. 2017;69(4):687-99.

52. Papavasileiou E, Prasad S, Freitag SK, Sobrin L, Lobo AM. Ipilimumab-induced ocular and orbital inflammation: a case series and review of the literature. Ocul Immunol Inflamm. 2016;24(2):140-6.

53. Antoun J, Titah C, Cochereau I. Ocular and orbital side-effects of checkpoint inhibitors: a review article. Curr Opin Oncol. 2016;28(4):288-94.

54. de Velasco G, Bermas B, Choueiri TK. Autoimmune arthropathy and uveitis as complications of programmed death 1 inhibitor treatment. Arthritis Rheumatol. 2016;68(2):556-7.

55. McElnea E, Ni Mhealoid A, Moran S, Kelly R, Fulcher T. Thyroid-like ophthalmopathy in a euthyroid patient receiving Ipilimumab. Orbit. 2014;33(6):424-7.

56. Modjtahedi BS, Maibach H, Park S. Multifocal bilateral choroidal neovascularization in a patient on ipilimumab for metastatic melanoma. Cutan Ocul Toxicol. 2013;32(4):341-3.

57. Martins F, Sykiotis GP, Maillard M, Fraga M, Ribi C, Kuntzer T, et al. New therapeutic perspectives to manage refractory immune checkpoint-related toxicities. Lancet Oncol. 2019;20(1):e54-e64.

Publisher's Note Springer Nature remains neutral with regard to jurisdictional claims in published maps and institutional affiliations. 